\title{
Dilemma of Study on Chinese National Traditional Sports Culture and the Selection of Paths
}

\author{
$\mathrm{Te} \mathrm{Bu}$ \\ Social Sports and Management, Tianjin University of Sport \\ Tianjin 300381, China \\ E-mail: buteagu@sina.com
}

\begin{abstract}
Any academic research is a kind of scientific exploration activities under direction of a certain methodology, with no exception in the case of modern sports science research, which refers to exploration on the general meaning and value system within the field of sports under direction of certain methodology and thought so as to promote sports activities developing towards a direction that is more favorable for human being. Sports science method is the bridge of transfer from sports theory to sports practice, which not only determines the level of sports scientific research achievements, but also affects development of sports practice and which will necessarily be improved and developed with progress of the society and with development of sports practice. To study and reflect on research methods of Chinese national traditional sports culture has profound significance to promote development of national traditional sports culture and to protect and inherit excellent sports culture heritage.
\end{abstract}

Keywords: Cultural self, Cultural self-confidence, Cultural self-consciousness

\section{Dilemma of research methods at present}

In recent years, some experts have made a statistical analysis in research methods of national traditional sports culture. According to Yu Zhonggan et al, "Chinese minority Sports study in recent years has still been focusing on literature research, but survey research and field research in sociology are also being emerging." (Yu Zhonggan \& Li Zhiqing, 2004) Considering the achievements of research by Han Suping et al, (Han Suping \& Tian Xiangying, 2009) field empirical method, survey and questionnaire method, literature research and mathematical statistics are the major methods to study national traditional sports, and these research methods have promoted progress of national traditional sports culture study, but still lag behind compared with the increasingly daily loss and extinction of national traditional sports culture encountered at present. There are several factors that cause the status quo of national traditional sports culture study and inappropriateness or lagging of research methods is, without doubt, one of the major reasons. We believe that the dilemmas encountered at present in research methods mainly include the following.

1.1 Dilemma of the selection of methods: more field survey and less cultural and philosophical analysis and more dependence upon statistical figures and less survey on in-depth practice

"Since later 1980s, the tide of academic circle has transferred from study on culture to study on existing institutional reform. Together with this favorable turn, sports social science field also transited from basic research as the major study to application research." (Qiu Jianrong, 2001) However, with development of anthropology of sports, there have been more and more applications in the research method of field survey. In the past few years, a kind of theory and description way has been prevailing in the field of anthropology of culture, namely, "thick description". (Clifford Geertz, 1999) Traditional sports culture research can borrow theory of "thick description" to improve deficiency of field survey research method. The theory of "thick description" is to attempt to acquire "translation" and "cutthrough" of different cultural explanation systems and pursue comprehension of cross-culture, which, as a matter of fact, refers to cultural and philosophical analysis. Cultural retrospection, cultural probing and cultural measurement of field survey is analysis of culture and philosophy. We should avoid confining the field of vision to superficial survey statistics, description and analysis in in-depth study on national traditional sports culture, but should try to fulfillment "thick description" and realize analysis and measurement at the cultural and philosophical level. there are also some other studies which make a classification on cultural characteristics of national traditional sports and study regional national sports 
tourism and development et al, based on "Records of Chinese National Traditional Sports" compiled in 1990. (Huang Cong \& Qiu Peixiang, 2008) Without doubt, the study to purely seek for a path for study on traditional culture from outdated books is inadvisable, since the era has progressed forward another 20 years, especially this period of 20 years is an accelerating period of the progress of Chinese urbanization. How is the existing status quo of traditional sports culture? For instance, how many items or schools does martial arts still have? We have to make an in-depth practical survey to grasp the firsthand material, otherwise our study is nothing but fantasy.

1.2 Dilemma of method idea: much focus on superficial research and less focus on analysis of internal study, and more study on cultural attachment and less study on cultural return

According to Yi Nike et al, in studies on traditional sporting events, there appears the phenomenon of seeking quick success and instant benefits with an emphasis on development of practical value. Restrained by western modern sports ideas, these studies focus on comparison between modern Olympic events and Chinese traditional sports events in terms of rules and competition, etc, but ignore the internal value of traditional sports events and extended development of entertainment and performance elements of national traditional sports as well as their cultural deposits and neglect in-depth theoretical study on national traditional sports, as a result of which in-depth innovation is caused that is deficient in accumulation of theoretical foundation. (Ni Yike, Shao Xiaojun \& Zhang Zizhi, 2005) At present, there exists such a phenomenon, that is, there are many studies that concentrate on the technology and set patterns of traditional sports, while there are relatively a few studies on internal rationality and value appeal of traditional sports culture and link between Chinese traditional culture and national traits. Quite a lot of studies attach great importance to the issue of attachment of traditional sports culture. For instance, it is believed that, a martial art can only find its way out by joining in the Olympic Games, and a pessimistic attitude is held towards failing to join in the Olympic Games. Both quantitative analysis qualitative depth is insufficient in studies of exploration of cultural return. Quite a large number of researchers have such an idea that traditional sports culture should be integrated and attached to western sports culture since western physical culture has its advancement and in such a way Olympic Games can be inherited and developed. Furthermore, the exam standard for sports colleges and universities to recruit undergraduates of martial arts is established totally in accordance with the standard mode of athletic martial arts. Thus, it is not difficult to find out our internal malpractice in the train thought of development of traditional sports culture. Although Olympic Games is far superior to the former Greek culture after its development for a hundred years, it is still the cultural system under the voice of western world, and it sometimes arouses worry of some academics in its destiny when it becomes the value tool of the western society with its commercialization and professionalization. However, from the perspective of cultural relativism, it is not an issue of progress or recession for a small nation or a weak nation and a majority nation. Hence, it is hegemony of dominant economy and rights of voice of dominant culture to evaluate existence and development of a culture merely with the quantification indexes of international influential strength, spread coverage and economic benefit. Excellent sports culture traditional of each country and each nation is a treasure of spiritual heritage of the whole human kind. Although countries and nations that assume culture and civilization are varied in size and all kinds of cultures and civilizations are developed in different orders, there is no distinction of relative superiority or inferiority, because they all deserve equal respect and protection of the whole human kind.

\subsection{Dilemma of inertia of method: more focus on scientificalness of culture and less focus on endogeneity of} culture

Studies at present are mainly concentrated on: 1) study on martial arts; 2) investigation in minority traditional sports by field work; 3) study on national traditional sports multi-culture; 4) protection on traditional sports cultural heritage. (Ni Yike \& Hu Xiaoming) Among these studies, more focus is put on study of the scientificalness of culture, while study on endogeneity of culture is ignored or seldom done. What we do most is to study and seek for rule of an object in scientific field, which is the inertia of our research method. Then, what is the rule of national traditional sports culture? It is difficult to find a convincing answer. It is believed, what we ought to do most is to seek for endogeneity of culture in study on traditional sports culture, that is, to find internal foundation and gene of existence and heritage of national traditional sports culture and to recognize its value system and value appeal. Some research achievements vigorously advocate the issue of standardization and modernization of traditional sports culture, and believe that low degree of standardization is the restraining factor for development of national traditional sports, which should arouse our high attention. Then, what should we take as the standard? Should we take value system of western competitive sports as the standardization? All these issues require serious treatment and objective analysis. Otherwise, national traditional sports culture might go towards the standardization of western sports, which will necessarily cause some decadent elements of western sports culture to spread unchecked on our territory and make the "cultural meme" of its excellent 
traditional sports to shrink and extinct. Just the same as the case that simplification of a species gene causes deterioration of the whole species, the above situation might cause diversity and creative strength of the global sports culture to gradually go to collapse. Then, how should we define the definition of modernization? From a cultural meaning, what kind of modernization should national traditional sports culture need? This is an issue which can't be avoided, but whose answer can not be found easily. It is believed by some one, modernization of the tribalism of tropical rain forest in Brazil means loss of the primitive culture of the tribe and it we intend to protect it, we ought to isolate it. So long as this primitive culture appears in TV programs, it will no longer exist, or it might exist merely as a pure scenic spot. Modernization, in a certain sense, means industrialization. Modernization of national traditional sports culture means loss of the original value system. Whether or not admitted, superficially, the so-called modernization means to modify the national traditional sports culture according to western sports standard and to make it routinized and stereotyped, which, to a great extent, is to adopt western cultural mode and which essentially means loss of "cultural self-consciousness" and replacement of the so-called advanced dominant culture. At the moment when globalization is conducted worldwide and promoted swiftly, it has become a great trend to arouse awakening of consciousness of national traditional sports culture. Thus, routinization and stereotype modification on national traditional sports culture is not modernization, but cruel damage. Modernization of traditional sports culture should be extension of the tradition and should bring into prominence its internal value idea that respects the nature and displays humanity, which exactly corresponds with the endogeneity of the main melody of the times and which is the modernization process that is integrated into the global trend of contemporary development.

Thus, when we study national traditional sports culture, we can not rest on the most superficial form of modern society, but should more explore the cultural connotation it exactly implies. When we discover some "primitive" national sports during our investigation, we should recognize and explain this culture in a correct way, rescue, protect, package, develop and exploit this culture, for which we have to study its origin and cultural essence. It is the potential value and superiority of historical anthropology in its study on national traditional sports not only to explore national sports culture, but also to recover or expound the national sports culture essence. (Huang Cong \& Qiu Peixiang, 2008)

\section{Study on the development path of variation of national traditional sports culture}

According to Fischer and Marcus, "with development of communications media at the end of the century and sudden change of the society as well as progress of science, culture is also changing. As a result, a situation appears that is greatly varied from the former cultural pattern, which urges anthropologists to give up their traditional methods and arguments, and transfer to discussion of new phenomena and new theories". (Na Ri Bi $\mathrm{Li} \mathrm{Ge,} \mathrm{2001)} \mathrm{With} \mathrm{continuous} \mathrm{reinforcement} \mathrm{of} \mathrm{our} \mathrm{comprehensive} \mathrm{national} \mathrm{strength,} \mathrm{the} \mathrm{spring} \mathrm{of} \mathrm{renaissance}$ and flourishing of traditional sports culture is approaching. For the time being, renaissance of national traditional sports culture is faced up with god-given historical opportunities. Firstly, development of the reform and opening up lays a solid material foundation for development of national traditional sports. Secondly, "cultural self-consciousness" gradually becomes the common view of the academic circle", and "cultural self-consciousness" and "cultural heritage" consciousness are also affecting the trend of development of national traditional sports culture. Thirdly, it is generally believed in the international sports world that the global sports is transferring towards the eastern world, which offers better environment for the international path of national traditional sports. In face of such a great times and historical opportunities, we should study the path of variation of traditional sports development. The development path of variation is to improve the cultural self-consciousness and cultural confidence of traditional sports culture under such a great background of globalization, seek for "self-esteem" of national traditional sports culture in development of cultural diversification development and control the orientation of "self-esteem" of our national traditional sports culture. Self-esteem of traditional sports culture includes the following three implications and levels: "development of oneself", "development of self-confidence" and "development of self-consciousness". In the following, we are going to give a specific analysis:

\subsection{Traditional sports culture should select the development path of "cultural self".}

Starting out from high sense of historical responsibility, Tan Hua subtly analyzed reasons for decline of Chinese traditional sports for more than a century and summarized two reasons: firstly, with gradual transition of Chinese society from the agricultural society to industrial society, the social foundation on which traditional sports depends on gradually disappears; secondly, modern sports set up based on modern industry and urban civilization is entering China with a strong pose and further presses the survival space of traditional sports. Therefore, we should set up a nation-oriented sports theoretical system to break away from control of western scientific voice system. In the mean while, we ought to draw lessons from experiences of European teams and 
Japanese traditional sports modernization to make necessary reform and classification on martial arts and enable martial arts to be better integrated with modern social life. We should also make an attempt to set up traditional sports ecological culture region that has the capacity of self survival. (Ni Yike \& Hu Xiaoming, 2009) We believe that not only Chinese martial arts, but all national traditional sports cultures should seek for a developmental path of "cultural self". Culture, is supposed to be "cultural self" of one nation, and culture will also lose its meaning of existence if it goes without "cultural self" of the nation. The developmental path of "cultural path" is to recognize the value of existence of "cultural self", discover the endogenous mechanism and soil of "cultural self" and improve the service level of "cultural level". Development of "cultural self" is the pre-condition for heritage and development of Chinese national traditional sports culture, and without this pre-condition, we will lose the footstone to be integrated into the international sports culture. Hence, we need to accelerate study on the developmental mode of "cultural self", create ecological culture regions for heritage and development of the national traditional sports culture, continuously strengthen the ability of creation and immunity of the national traditional sports culture and let it have the sustainable vitality.

\subsection{National traditional sports culture should select the developmental path of "cultural self-confidence".}

In the process of cultural globalization, struggle for culture, loss and even extinction of culture has become a reality that can't be avoided. Traditional martial arts which bear Chinese traditional cultural quintessence are faced up with a series of crises in the era of struggle for culture, which is represented as a kind of discomfort and helplessness. We should conduct high cultural evaluation on Chinese traditional martial arts, explore its potential monstrous cultural value and make traditional martial arts irradiate in struggle for culture. (Ma Wenguo \& Qiu Peixiang, 2006) In face of such an austere situation, we believe that a system of "cultural self-confidence" should be established in Chinese traditional sports culture centered with martial arts, in which we should select the development path of "cultural self-confidence", which is a necessary choice for cultural globalization. $\mathrm{Mr}$. Lu Xun said, "the more one is national, the more it is international". This indicates particularity and self-confidence of a national culture. When we are faced up with the major trend of globalization, we have to think whether peculiarity of national traditional sports culture can still be maintained? What's the significance of maintaining cultural peculiarity? Previously, it was believed that, cultural globalization was a process of struggle between dominant culture and weak culture. "As a matter of fact, we would rather say that a competitive platform in a flat world is more potentially powerful to enable the world to be diversified in an unprecedented way than say that it can assimilate all kinds of culture." (Thomas L. Friedman, 2006) Since national traditional sports culture and its components can be maintained until now, they must have their own value or usefulness, and it is exactly existence of this kind of value that the culture can be inherited until today and has its future. China national traditional sports culture is an independent system, which can't be compared with the tradition and value system of western sports culture, because they don't have a universal equivalent. Considering this fact, we should see the "self-confidence" of China national traditional sports culture, and it is under promotion of this kind of "self-confidence" that the national traditional sports culture has been development until now. Mr. Zhu Qianzhi verified in "Influence of China Philosophy on European Culture" that the Enlightenment in Europe in the Eighteenth Century had been enlightened to great extent by Chinese culture. Contemporarily, the connotation of national traditional sports culture to uphold the nature, to be harmonious and tolerant and to be human affects development of western competitive sports and makes it transited and development in the eastern part of world. Especially, China traditional martial arts have rich cultural connotation and strong cultural vitality and embody the ideological quintessence and leading spirit of Chinese culture from fundamental theory to technical application. Thus, international dissemination of martial arts should have high cultural self-confidence, in which way can development of traditional martial arts in the future be filled with hope and vitality. (Ma Wenguo \& Qiu Peixiang, 2006)

\subsection{National traditional sports culture should select the development path of "cultural self-consciousness".}

The famous scholar Fei Xiaotong put forward the idea of "cultural self-consciousness" for the first time. "Cultural self- consciousness means that people in a certain culture know their distance and have sufficient knowledge in its development progress and future. In the mean while, cultural self-consciousness also means that people living in different cultures know about the relations between other cultures and their own culture on the basis of knowing their own distance." (Fei Xiaotong, 1998) We believe that national traditional sports culture heritage and development should select the developmental path of "cultural self-consciousness", since only development of "cultural self-consciousness" can make one realize "self status" and characteristics, find out "self position" and improve the independent capacity of cultural transition. As early as in his study on culture of traditional martial arts, Wang Gang proposed the concept of "culture self-esteem" in martial arts, and believed that as the sports cultures in eastern and western regions, both Chinese martial arts and Olympics had their own 
characteristics and dignity. As for martial arts, self-esteem of culture is to keep the excellent tradition of national culture. By contrast, as for Olympics, the self-esteem of culture is to come off its perch and look upon the sports culture of other nations with an open mind. (Wang Gang, 2004) It is a great trend for the China national traditional sports culture with the subject of martial arts to be integrated into the global diversified cultural system represented by Olympic Games. However, how to be integrated into the global cultural system ought to be a historical subject that deserves serious research. The process of heritage of national traditional sports culture is also a process of being integrated into the global sports culture and is more a development process of "cultural self-consciousness" to keep its own cultural characteristics and dignity. If a national traditional sports culture loses its characteristics and dignity, then it is not in a position to discuss "cultural self-consciousness". "Cultural self-consciousness" of national traditional sports has presented different historical features in different historical periods, for which Guo Yucheng classified into three historical periods. The first period is the Republic of China era in which martial arts were named as kungfu and played the role of strengthening the country and the nation and activating the national spirits. In the 80 s in the Twentieth Century, the national sports commission organized excavation and classification of martial arts and in 2004, the first world traditional martial arts festival was held. (Guo Yucheng, 2007) Sports culture is not an economic phenomenon, and even if it is in an inferior position, it can still send out its radiance. To a certain extent, cultural globalization and cultural hegemony may stimulate cultural self-consciousness. At the same time, heritage of traditional sports culture also depends on the nation itself to cherish the culture with consciousness. Thus, we ought to attempt to pursue innovation and change, and try to realize heritage in innovation and innovation in heritage.

\section{Study on heritage path of traditional sports culture}

National traditional sports cultural heritage and development is a systematic project, which not only involves the sports field, but also requires the atmosphere built by the large environment of the society. We should strengthen vigor on study of paths of national traditional sports cultural heritage and seek for heritage paths in the entire social systematic system. For the time being, we believe that we should reinforce study and breakthrough from the following several aspects.

3.1 To set up the guarantee system of traditional sports cultural heritage and development with national protection policy as the core

The key to the traditional cultural conservation and heritage of any nation is the external environment of a nation and a society, which calls for formulation of an active, constructive, favorable and protective national cultural policy. For study of traditional sports culture, we seldom concern ourselves with policies, measures and capital, etc, but always have an empty talk of strategies. Strategy needs policies, measures and capital as the guarantee, and, otherwise, strategy is merely a bank sheet. Heritage of traditional sports culture needs the national policy system as the guarantee, so it should be brought into the entire traditional culture protection and establishment system of the country. It is suggested that the country make a certain amount of capital to set up "national traditional sports cultural protection funds", secure the sports inheritance that is on the verge of extinction and loss and develop and inherit sports culture in a planned and organized way.

3.2 To intensify the cornerstone of traditional sports cultural heritage and development with the starting point of popularization among young people

"Without human being, even the best text will have to become a dead culture, and will even be buried in the track of history". (Wang Gang, 2006) Faced up with the severe attack of western competitive sports and sports commercialization and acceleration of industrialization and urbanization, traditional culture background gradually disappears and heritage of traditional sports culture has become the focus of attention in the sports field and even across the whole country. As a traditional culture, sports can be developed and full of vitality only if it is passed down from generation to generation. Hence, hope of traditional sports culture is young people and its future is also young people. Without young people, heritage of culture is just a castle in the air. "There are more than 300 million young people in China, and school is the best and most extensive battlefield to inherit martial arts. Thus, only if we put martial arts in the school to inherit through young people, can we better perform the historical mission to propagate national spirits and inherit Chinese traditional culture." (Qiu Peixiang, 2006) South Korea regards Taekwondo as a compulsory national subject for education for each student, including overseas students, which should have greatly enlightened us. For example, we isolate martial arts from the sports class of the school and regard it as a compulsory national course for each students, which will have an enormous stimulative effect upon heritage and propagation of national culture and national spirtits. 


\subsection{To improve the momentum of traditional sports cultural heritage and development with dissemination among the public as the focus}

Why did some competitive culture of China disappear all of a sudden in the history, such as, ancient kemari and especially polo? This is a problem that has been perplexing sports historians all the time. It is analyzed to include the following several reasons: "This has something to do with the fact that gradual collapse of hereditary peerage system (Shizi system) since Tang Dynasty made kemari and polo that were major noble activities loss their carrier and successors. As a matter of fact, temporary decline of I-go in the modern society is also as a result of the above reason. However, the reason that dragon boat and martial arts have survived long is that they live in folk, but not in the imperial court." (Hu Er, 2003) The public is the subject of dissemination of sports culture. Thus, heritage of traditional national sports culture should neither remain on academic research, nor be limited to the campus, but should become the cultural consumption of the extensive public and become one of the primary living means of human being, which is the original momentum of heritage and development. Traditional sports culture ought to be combined with implementation of "Outline of Fitness of the Nation". And heritage and development of traditional sports culture should be integrated into the health activity of the whole nation, in which way it can be rooted and blossom among the extensive public and keep its vitality for development.

\subsection{To extend the chain of traditional sports cultural heritage and development with diversified dissemination as the channel}

The current era is one of informationization and networking, and any national culture can be spread to each corner of the world through network dissemination. In the mean time, this era is also a development era which highlights tolerance. Globally speaking, all countries should respect each other, since we can find a path of globalization only on the basis of respecting others' culture. In the process of globalization, there is not any national culture that is as pure as it was, as it has been embraced within an integration without consciousness. Thus, if there is no tolerance, there would be no means to establish culture of one's own if an attitude of resistance is taken towards culture of others. In such an atmosphere of globalization, we can consider take advantage of the platform of Olympics to disseminate national traditional sports culture, but we should not remain merely on this point. On the contrary, we should establish sports traditional cultural digital protection system and network spreading channel, so as to expand the influence of cultural dissemination.

Anthropology advocates that, in the process of cultural dissemination, different national cultures should absorb cultural features and cultural systems of each other with choice. This kind of education is quite necessary under the great background of globalization, opening up and reform and market economy. The feature of traditional sports culture is interaction and communication. We should not close the door of communication to the culture just because we want to protect its cultural feature and pattern or just because it hasn't been selected as one of the Olympic competition items, because this kind of isolation and closeness might weaken its vitality. At the same time, traditional sports culture can only be full of innovative spirit in communication. In face of attack by dominant cultures, the key to development of traditional sports culture is to acquire "self" cultural development in civilized communication and conversation, to strengthen "self" cultural confidence in development and to improve "self" cultural consciousness in self-confidence. In this way, more and more people will come to understand and acknowledge Chinese traditional national sports culture and disseminate it to the whole world. Then, not only value of culture, but also value of economy will be highlighted. Just as Mr. Ji Xianlin said, "The $21^{\text {st }}$ Century is a century of eastern culture, and the dominant western culture will gradually give place to eastern culture that has been in an inferior position. Whether or not agreed, there is one point that is sure. That is, eastern culture that is centered with traditional Chinese culture will play a more and more important role on the stage of the world." (Ji Xianlin, 2001)

\section{References}

Clifford Geertz. (1999). The Interpretation of Cultures, translated by Nari Bilige, et al. Shanghai: Shanghai People's Publishing House.

Fei, Xiaotong. (1998). From Reflection to Cultural Self-consciousness and Communication. Reading, (11).

Guo, Yucheng. (2007). Cultural Self-consciousness in Spread of Martial Arts: From Going out of Tradition to Discover Tradition. China Sport Science and Technology, (1):25-28.

Han, Suping \& Tian, Xiangying. (2009). Analysis of Scientific Research Documents of Chinese Ethnic Traditional Sports from the year 1999 to the year 2007. Journal of Chengdu Sport University, (2).

Hu, Er. (2003). Sports: Going towards the Whole Human Kind. Sports Culture Guide, (1).

Huang, Cong \& Qiu, Peixiang. (2008). Study on National Traditional Sports from the Perspective of Historical 
Anthropology. Journal of Xi'an Institute of Physical Education, (4).

Ji, Xianlin. (2001). Discussion by Cultural Experts in the $21^{\text {st }}$ Century. Spiritual Civilization Construction, (1).

Ma, Wenguo \& Qiu, Peixiang. (2006). An Era of Struggle for Culture: Helplessness of Traditional Martial Arts. Journal of Xi'an Institute of Physical Education, (5).

Ma, Wenguo \& Qiu, Peixiang. (2006). Self-confidence of Culture: Hope of Traditional Martial Arts. Journal of Xi'an Institute of Physical Education, (6):1-4.

Na Ri Bi Li Ge. (2001). New Pattern of Anthropology Theory. Beijing: Social Sciences Academic Press.

Ni, Yike \& Hu, Xiaoming. (2009). China Sports Anthropology in Its Development. Sports Science, (10).

Ni, Yike, Shao, Xiaojun \& Zhang, Zizhi. (2005). Theoretical Foundation of Construction of National T raditional Sports Subjects. Sports Science, (1):25.

Qiu, Jianrong. (2001). Loneliness is not Solitude --- Review on "Sports Anthropology". Sports Culture Guide, (1).

Qiu, Peixiang. (2006). Thought on Development of National Sports Culture under the Background of Global culture. China Sport Science and Technology, (8):63-66.

Thomas L. Friedman. (2006). The World is Flat, translated by He, Fan, et al. Hunan Science \& Technology Press, September, 374.

Wang, Gang. (2004). Self-esteem of Culture. Wushu Science, (6):1-2.

Wang, Gang. (2006). Attention to the Subject of Martial Arts Heritage: Human Being. Wushu Science, (12).

Yu, Zhonggan \& Li, Zhiqing. (2004). Evaluation on Our National Minority Sports Research in Recent Ten years. Sport Science, (10). 